\title{
A Tale of Two Libraries: Space and Reading in Porto Public Libraries
}

\author{
Paula Sequeiros \\ Librarian, Researcher with the Instituto de Sociologia, University of Porto, \\ Porto, Portugal \\ and \\ Silvia Grünig \\ Architect and Urbanist, Pedagogic consultant at the Universitat Oberta de \\ Catalunya, Barcelona, Spain
}

\section{Introduction}

Until 2001, people in Porto, Portugal could only visit or borrow books from one library - São Lázaro - located where the historical centre and the eastern end of the city meet. Then, a new building, the Almeida Garrett Library, was designed and placed in an almost equidistant position between the historical centre and the western zone. Both buildings and their reading atmospheres are quite different. Readers and professionals tend to compare them. And so the question arises: how do two different architectural spaces shape reading practices, even though they are inserted in the same city and serving potentially similar readers? The question sought to explore the interaction between people and space, in other words, how a space provided for reading may be appropriated, how it shapes reading practices, and, what social relations are performed in such reading spaces.

Buildings tend to reflect both public reading and local cultural policies, even though the use of the space may alter and circumvent the programmed institutional aims. This analysis of space usage takes into account such policies and actual reading practices, along with their meanings and emotions. Social issues such as class, gender, ethnicity, age and power relationships provided a context for this analysis. As the public services and public buildings were analyzed, a research approach was designed to place reading in the context of urban public space, urban conviviality and the importance of democratic places for encounter and discovery.

\section{Theoretical Framework}

The places where one chooses to read are expected to provide a certain level of comfort and privacy. From the space where one reads one builds mental spaces 
for mentally intense activities. Defining space was the first step in building a theory on the interaction of people in the course of reading and space.

With respect to space and social life Lefèbvre writes:

"[Social] space is not a thing among other things, nor a product among other products; rather it subsumes things produced, and encompasses their interrelationships in their coexistence and simultaneity - (relative) order and/or (relative) disorder. ... Itself the outcome of past actions, social space permits fresh actions to occur, while suggesting others and prohibiting yet others" (Lefèbvre 1991).

Synthetically, Lefèbvre posits that space is, simultaneously, the product of social practices, as well as of economic, political and scientific representations "the representations of space" - and a set of cultural codes conveying images, mythical narrations, cultural symbolic expressions - or "the representational spaces" (ibid).

From his Marxist perspective, space as a commodity, is both a product and the means of production of social relations. The naturally perceived, visual, abstract and yet reified character of space, easily surfaces. Space is engendered by and reflects power relations. So, appropriated space must also be considered and not only the space of property. While unveiling that social relations exist only in and through space, this framework stresses the importance of space use and its qualitative properties, promoting not only the knowledge of space, but also a critique of its use.

\section{Space, Visibility and Space Legibility}

The constant bombardment of images, characteristic of our times, obscures the contribution that social relations have in producing and reproducing space. Being an abstract concept, space is a difficult theme to address through discourse. To overcome this abstraction, rhetorical devices, such as metaphors, are used in everyday speech requiring analysis in order to understand their deeper meanings. Technicist or purely aesthetic approaches disregard content, favoring vision from, but not a reflection on space. Lefèbvre's triadic model, interconnecting space as perceived-conceived-lived, allows for a holistic, combined focus on form, structure and function.

\section{Space, Property and Spatial Appropriation}

The concept of appropriation is central to Certeau's thought (1984) since people may behave in different ways within a single place and may eventually transform the place. Certeau also claims that space, as seized by vision, may conceal more than it may reveal. So, everyday life spatial practices should be 
addressed rather as "a specific form of operations (ways of operating)" which favors "another spatiality (an anthropological, poetic and mythic experience of space)". Instead, kinesthesis and emotions need to be brought together to feel the created space.

To understand how appropriation is performed, the concepts of strategy and tactics are advanced. Use is opposed to consumption: the latter is tied to those with the power to impose an order on culture, to commercialize products; the former is tied to persistent practices, the everyday life ruses of those using the products, resistance and maneuvering. In a dynamic network of power relations, different interests and desires may lead to unreasonable uses of a predefined space. How space is used may be more relevant, then, than what is used. Strategy is a calculus of force-relationships made possible by conceptually isolating a subject, with will and power (institution, city, enterprise) from the environment. Strategy asks for a place circumscribed as a proper - of one's own - from where to operate rationally, connecting to or opposing the external environment (ibid). Tactics is the calculated action of those who, lacking a proper, use the place of others. "In short, a tactic is the art of the weak", a movement within the enemy's panoptical field of vision" (ibid).

This methodological framework allows researchers to overcome an exclusive or excessive focus on homogenization and repression, and to understand what real people really do.

\section{Place and Action}

According to Certeau, while "space occurs as the effect produced by the operations that orient it, situate it, temporize it, and make it function in a polyvalent unity of conflictual programs or contractual proximities", "place is a practiced space". The discourse on travelling oscillates between either seeing or going, while the discourse on walking, through an apartment or street, centers around trajectories. A method for reading, the making of space and place is therefore proposed, along with references to a pre-established geography.

In an analogy between walking, reading a text or narrating a story, the narrative's role is directed to surpassing the illegibility of space and focusing on a "theatre of the legitimacy for effective actions". The region - a "space created by an interaction" - is to be taken as the unit of analysis, morphology is to be set aside, and pragmatics and syntax to be applied to "programs or series of practices through which space is appropriated".

These combined perspectives of social space in relation to practices and to negotiation or conflict are particularly fruitful in times and situations where spaces are becoming increasingly polyvalent. And more so, as the perspective of readers themselves and their protagonism, is fundamental to a commitment to intervention and social change. 


\section{Methodology}

The next concern was to link facts to processes, individuals to social relations, through a reflexive approach that would take into account the social contexts of their occurrence. Another concern was to create intersubjectivity among subjects and objects of knowledge through dialogue by focusing on theories of self, their values and meanings and on their actual practices and discourses (Donmoyer 2000). An integrated, qualitative approach was designed, directed at the social actors' actual practices and their interpretation (Blumer 1969; Geertz 1975).

For each site analysis, Burawoy's Extended Case Method (1998) was adopted. This method privileges the transferability of knowledge produced from singular situations, as opposed to the traditional concept of generalizability, tied to the statistical analysis of extensive quantitative data from several cases. Just as an individual may learn from vicarious experiences, so may people learn from single cases, given the fittingness of conclusions. This main advantage of this method is a combination of in-depth analysis with context insertion, linking the unique to the whole society, thus providing for rich interpretations. Later, each case's data was compared in a table for a simpler visual perception of similarities and differences.

Seeking strong ethnographic support, observation (Seale 2004) and indepth semi-structured interview techniques (Kvale 1996) were applied. Theoretical samples were constructed according to the perceived social diversity (class, gender, age, education, ethnicity, disabilities). Twenty-eight users, two library managers, one assistant librarian, the maintenance supervisor, and the architect were interviewed in Almeida Garrett (AG). In São Lázaro (SL), interviews were conducted with twenty-two users, two managers and three architects. Young children were analysed through informal conversations with them and their relatives and through drawings done by them on "what is a library" (Eder and Fingerson 2002). Field work in AG was conducted between the end of 2008 and mid 2010, while in SL it was done during February and March 2008 and from May to July 2010. The buildings were analyzed aesthetically and functionally as was their urban insertion.

A commitment to the intentionality of the constructed object and the purposes of the research, the authors assume favoring the provision of democratic spaces for public reading as a relevant public service (Haraway 1991). They also assume that such spaces are to be enjoyed for conviviality, culture, leisure, information or learning by all citizens alike. 


\section{The City as Context}

In terms of population, Porto is the second largest city in Portugal, with over 260,000 inhabitants. It spreads along on the right bank of the Douro River, where the river meets the ocean. An Atlantic climate which is humid and moderate with some cool nights wraps the city. Frequent rainfall and mist, mostly in the mornings, are characteristics of the cooler seasons. The city is historically renowned for its local and international trade, particularly the port wine business. Today, Porto reveals an important but persistent trait: it has been losing population since the 1960 s, especially young people who migrate to surrounding municipalities where housing is cheaper.

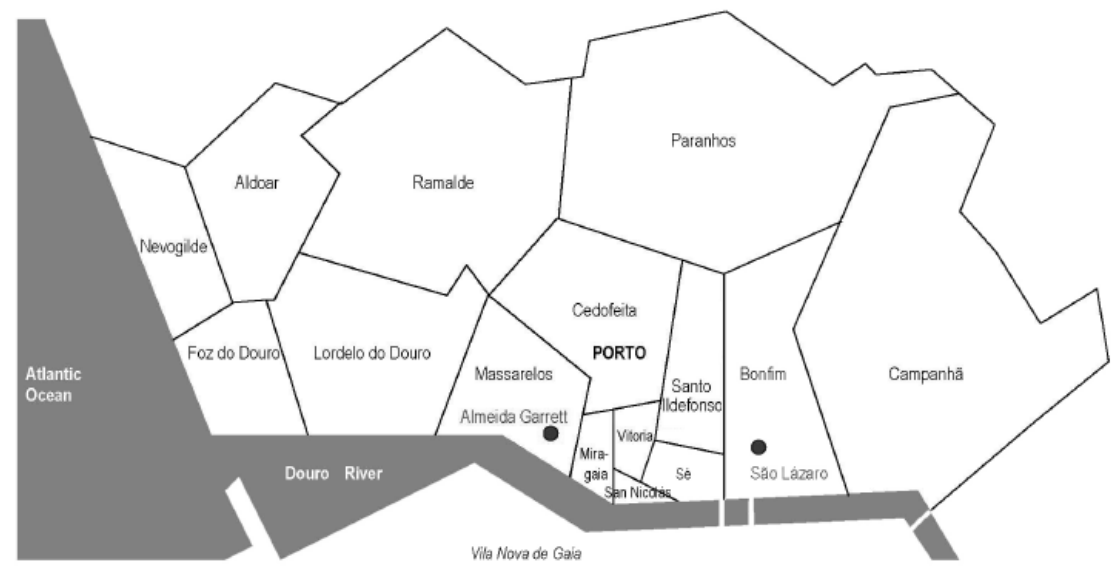

Figure 1: Porto and the location of the two libraries

As a cohort, the elderly of Porto exceed the national average. Ageing is particularly noticeable in the progressively abandoned historical centre (Sé, S. Nicolau, Vitória and Miragaia parishes). In Porto, small families predominate $(67 \%)^{1}$ and people living alone (18\%) outnumber those in neighboring municipalities, both indicators registered a noticeable growth in the 1990s. A similar comparison can be made with regard to childless or mono-parental families (Pereira 2005, 2006). Economic life presents an internal differentiation and a singularity: $70.4 \%$ of the economically active are employed in the tertiary sector, compared to $40 \%$ in the North Region.

1 All quantitative data is taken from the 1991 census. 
The last decades have witnessed a process of de-industrialization, while the middle-class maintained considerable relative weight. Significant changes have occurred during the period 1981-1991. In 1991, the entrepreneurial small bourgeoisie accounted for $35.6 \%$ (42.6\% in 1981) of the population; intellectual and scientific professionals accounted for $13.2 \%$ of the population $(14.2 \%$ in 1981); those occupied as industrial workers represented $27 \%$ of the population (as against $19.9 \%$ in 1981). Porto is now a "city of clerks and service workers, with a remarkable presence of members of the intellectual and scientific petite bourgeoisie as well as managers" (Pereira 2006).

Social housing projects, built around previous city limits, became the destination for those who were forced to leave the city centre. These are mainly the less educated workers. These housing projects represent the younger face of the city and are tied to industry. The older face being the historical centre and Campanhã, both of which have higher population densities. The unemployment rate is $6.9 \%$ which is higher than the rest of the country. In terms of unemployment rates, the old city and Campanhã account for $8 \%$ and $10 \%$ respectively and the metropolitan area, $6 \%$. Precarious jobs provide employment for about $15 \%$ of the population. Persons engaged in qualified professional activities are unevenly distributed across the parishes.

In terms of education, $14.8 \%$ of Porto's population holds a university degree - this is a higher rate than the rest of the country and nearby rural areas. These credentials are again unevenly distributed, higher qualifications range from almost $30 \%$ to only $3 \%$ or $5 \%$ in different parishes. Among women working for a wage, $21 \%$ have higher education. Of those living in the historical centre, half of them went to primary school only. The basic illiteracy rate in Porto is $4.3 \%$, whereas the national level is $8.6 \%$. In the historical centre it is $6 \%$ and in Campanhã it is $7.8 \%$. In terms of ownership of books in homes, $40 \%$ of families have between 10 to 30 books at home. This equates with the percentage of the population that represents the most economically fragile. $10 \%$ have no books at home; and, an intermediate group, $28 \%$ of the population has between 31 to 100 books in their homes. Those owning more than 500 books are predominantly intellectuals and professionals in the sciences. It should be noted that "a strong domesticity of practices (free time routines and receptive domestic leisure)" is to be found (Pereira 2006).

The socially depressed areas of the historical centre and Campanhã account for a voting preference to the left, with few persons from these areas voting right-wing. Nevogilde votes predominantly to the right. Other parishes vote to the centre, centre/left.

In terms of religious beliefs and practices, $80 \%$ declared that they were Catholic. Among these, 29\% do not attend institutional rituals, about a third on occasion, many preferring to pray individually. 


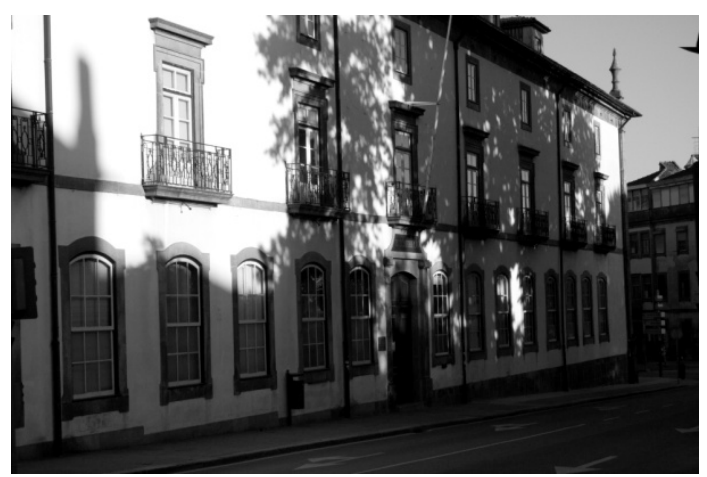

Figure 2: S. Lázaro Library, main façade (RSC)

\section{Results and Discussion}

\section{Urban insertion}

\section{São Lázaro Public Library}

Since 1841, the Municipal Library of São Lázaro has occupied a two-storied baroque building dating from the end of the 18th century. Formerly, the building housed the Santo António convent. The building is located in the parish of Bonfim, near the historical centre and it is also close to the most economically disadvantaged zones (Campanhã and the historical centre). The Municipal Library of São Lázaro was one of the first public libraries in Portugal. Historically, it is tied to the 19th century Liberal revolution, when the properties of religious orders were confiscated, including their rich libraries. As a consequence of Porto's strategic role in the Wars, several men of importance demanded that the winning sovereign, Pedro IV, create a library in the town. Among these men were lecturers and members of the Royal Academy of Merchant Navy and Commerce, a predecessor to the University of Porto (Santos 2006). João Baptista Ribeiro, Director of the School of Arts and the painter of a portrait of King Pedro IV, was one of the men who petitioned for the library. Several of the early librarians were recruited from the Academy. The library was officially inaugurated in 1842, on the first anniversary of victory over the Absolutists (Bruno 1906). The Royal Decree establishing the library stated that is was conceived as a "complement to the instruction system" (Biblioteca Pública Municipal do Porto 1984). In 1876 it became a municipal institution.

According to the original purpose, the exterior is austere, massive, with a pitched tiled roof and a central patio. The walls are painted white and the openings are framed with darkened granite. The building is in a reasonable state of conservation, especially the main façade and the part that is on Rodrigues de Freitas Av. Other façades had several volumetric additions over time 
eventually turning the whole into an impenetrable structure. Architectural interventions, according to the needs of the day, have been carried out at different times by several architectural teams. The main entrance is located opposite to the São Lázaro garden, from which the building takes its popular designation. The central front door on D. João IV St. may be reached through a narrow side-walk. A lateral door, in Morgado de Mateus St., gives way to the auditorium on the upper floor.

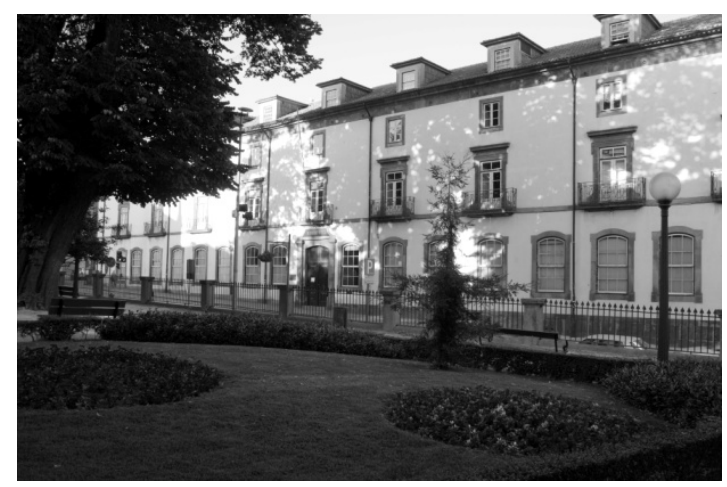

Figure 3: S. Lázaro Garden, facing the library entrance (RSC)

The well-used gated garden may be reached from any side. Groups of elderly men may be seen there during the day, frequently playing cards. When one looks at the complex, there is no apparent relation, not even visually, between the garden and the library. The architect who was interviewed declared: "The inside-outside relation has always been despised" in spite of being "a library with public access; the relation to the city should be relevant" (Tasso de Sousa). Another admitted that the urban insertion into the library's space did not bother him because "a library's time is not public, it belongs to those working there who have to know what they're dealing with" (João Carreira).

The initial plans for the building aimed at creating a cultural, scientific and leisure complex, including a museum, the library and the Arts School. It was also envisioned that there would be exhibitions of plants used locally in agriculture, arts and pharmacy in the opposite garden (Biblioteca Pública Municipal do Porto 1933).

The library is easily accessed by public transportation.

\section{The Almeida Garrett Public Library}

The new library was built closer to the western area of the city, in the parish of Massarelos. It is about a fifteen minutes walk from the other library. This is a more modern centre, the preferred location for the headquarters of service businesses and it is less than double the distance from the historical centre. In 
2001, a ten year-old project was begun, taking advantage of the financial opportunities provided by Porto's nomination as the European Capital of Culture.

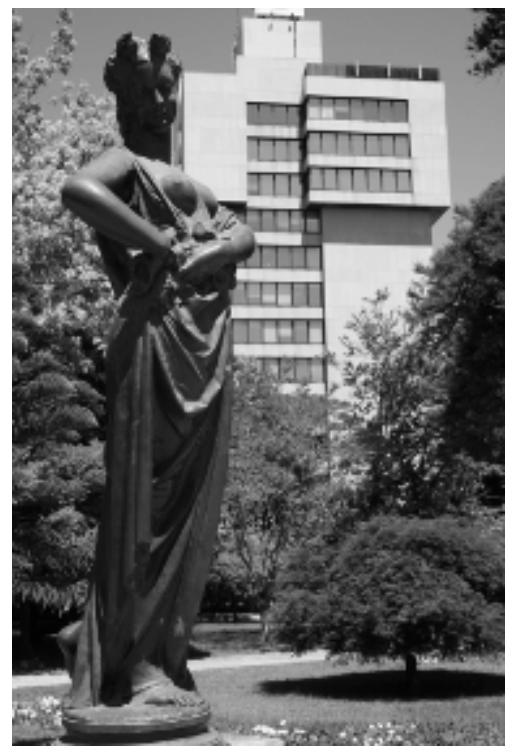

Figure 4: 'Spring' statue (RSC)

The new building was inserted in the city's largest public park, Palácio de Cristal $^{2}$, with an area of approximately $0.1 \mathrm{~km}^{2}$. The recently re-qualified garden maintains its romantic layout of paths and the cultivation of important vegetable species. This vegetation includes a multitude of magnificent sized centenarian trees. Due to the site's altitude, the park has a privileged view over the Douro River. A huge domed pavilion, built in 1956, replaced the 19th century iron-and-glass Crystal Palace, after which the park was named. There is also a children's playground. The Palácio is a frequent leisure destination, especially for families with children. The area is served by a well-developed public transportation system.

The main concern of the architect, José Manuel Soares, was "to bring a garden into the library without carrying a building into the garden". The main façade of UV filtering glass is disguised by a curtain of halved pine wood logs aligned transversally, preventing over-exposure to sunlight and allowing for "transparency" towards the garden and "maintaining a relation with the surroundings and the specificity of the place." The building occupies an area of $900 \mathrm{~m}^{2}$.

2 The Palácio de Cristal is also referred to as the Palácio or Crystal Palace. 
This chapter proceeds to present a comparison of results collected on an item by item basis, comments collected at both libraries - AG and SL - as well as the authors' interpretation of the findings.

\section{Inserted or dis-inserted?}

Almost all of those interviewed use public transportation or walk to get to the library: many of those interviewed live in neighboring cities. AG's location in the park is appreciated, "it's integrated in Nature", and even if the entire park is not visited, the garden "ease[s] your mind". While adults rarely use the park, children make considerable use of it. Reading may be so absorbing that even large peacocks walking along the windows may pass unnoticed.

SL's garden is not used by readers; library and park goers ignore each other. An African immigrant confessed his uneasiness and personal fear as near-by streets have a reputation for being frequented by "prostitutes and drunken men". Although unwanted - and even frequently silenced as inconvenient - SL's relation with surrounding city zones may be sensed and is still socially traceable.

Space Provided - Concepts, Form and Function

\section{São Lázaro}

Consequent to its inauguration in 1842 , special reading services were implemented during the last century: a Children's Library and a Female Reading Room in 1945. In 1973, a library for the visually impaired was completed. It should be noted that projects to create small libraries for public leisure in other city areas were not continued or ever implemented (Biblioteca Pública Municipal do Porto 1984).

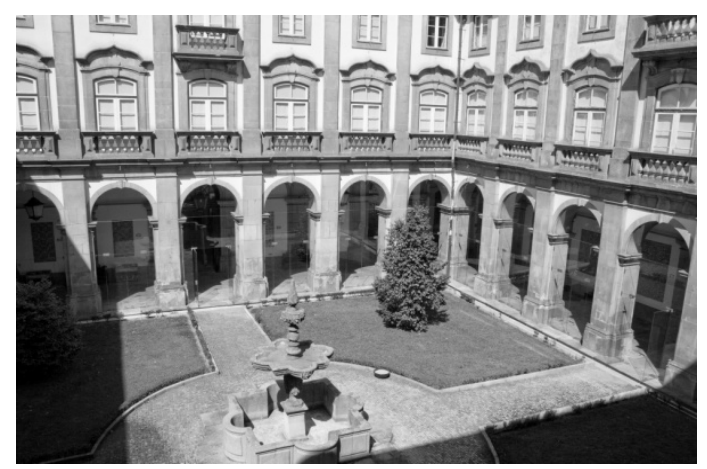

Figure 6: S. Lázaro’s Patio (RCS) 
The reception hall has been recently renovated. The granite on the floor and walls contrasts sharply with the large laminated white counter desk and the milky white acrylic units that are used as lockers. Important personal belongings may only be carried into the library in a transparent plastic bag provided by the library. There is abundant lighting throughout.

The ground level has a corridor around a gardened patio which has a centrally placed Baroque fountain. Glazed tiles from different places decorate the walls with their naturalist Baroque paintings. In a corner there is a vending machine for beverages and snacks. In order to smoke, some people go into the patio which is enclosed by glass doors. Other than that the patio is unvisited. A sign points to the Children's Library. All other public rooms are upstairs. Storage for the collection, with no public access, is on the lower level. A granite staircase, showing signs of considerable use, leads to the hall above. The hall is decorated with carved cabinets, tables and chairs made from ancient dark oak. From there one reaches other areas of the library: the free-access reading room; the catalog room with an Internet area and photocopying services; the serials room, presently closed due to a reduction in staff; and, the general reading room which is the main and largest area in the library. Wireless Internet is not available. An elevator connecting the hall to the stacks is intended for staff use only, but disabled readers are allowed to use it.

The three recent and main architectural interventions are as follows: the free-access and catalog room (Tasso de Sousa); a children's library (Souto de Moura); and, a general reading room (João Carreira). They were separately conceived. Statements of the architects on their work are presented below:

- "It's a building composed room by room and year by year, with partial interventions, with a fortuitous dynamics, with a lack of logic, completely the opposite of a whole, organic building" (João Carreira).

- In spite of being "very favorable to the exposition of diachronies", they are so frequent and "uncontrolled", that maybe the building has now reached a "certain chaotic appearance", with an interior not corresponding to the exterior volume, following a summing up of interventions (Tasso de Sousa).

Tasso de Sousa also remarked that no concepts, quality standards or guidelines were given to him with respect to the interventions he created and which were completed in 2001. Theft prevention and the maximization of shelving space were the major concerns. A constraint was the nature of the interventions, "not on a whole building" but directed at specific problems through "momentary responses". Born in 1941, Tasso de Sousa was inspired by Michael Brawn-Riba, 
Gunnar Asplund's public library in Stockholm, the 18th century university library of Coimbra, or, "symbolically", that of Eco's ${ }^{3}$.

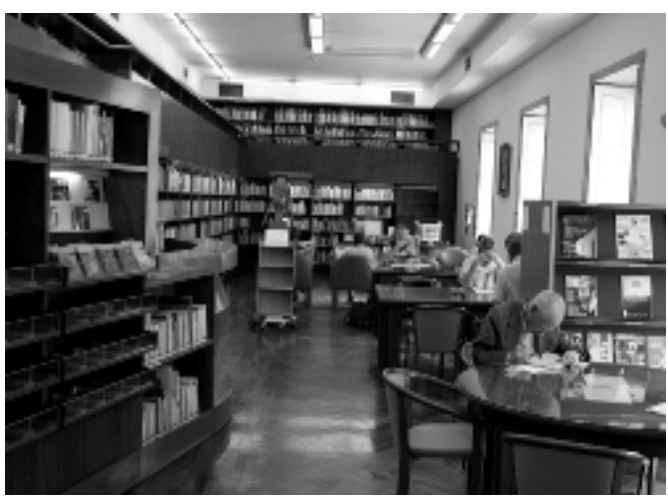

Figure 7: Free access room in SL (RSC)

The free-access room has a staff desk facing two round large tables for reading serials, two rows of facing tables and an Internet area with several desks at the far end, totaling 32 seats. To the left, a narrow mezzanine, lined with shelves, borders two sides of the room, using the space to its full advantage. A few multimedia items are displayed. Access to the toilets is gained through the entrance.

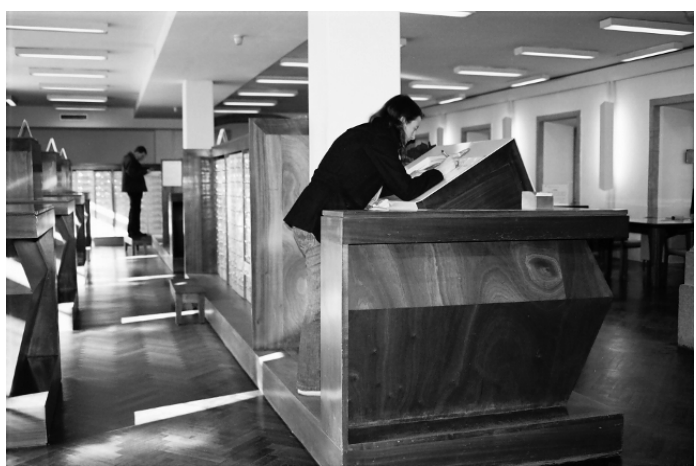

Figure 8: Using the card catalog

The catalog room is a long corridor with the card catalog cabinets and the manuscript catalogs on one side, an Internet area on the other, and the photocopying

3 In his book, The Name of the Rose, Umberto Eco describes a labyrinthine library in a medieval monastery where especially coveted and forbidden books were hidden. Access to these books was protected by secrecy and all kinds of traps including mortal ones. 
desk at the end. There are three generations of catalogs that one has to consult in order to access the collection of 1.5 million titles. These are a catalog published as books; a card catalog; and, from 1991 onwards an electronic catalog.

The space "was modeled with the cabinets themselves" says the architect who covered them in dark wood simulating a monk's cell, evoking the ambiance of the former convent. The idea was to provide "comfortable access" to the filing cabinets from an elevated platform, but a stool is needed to reach the top drawers.

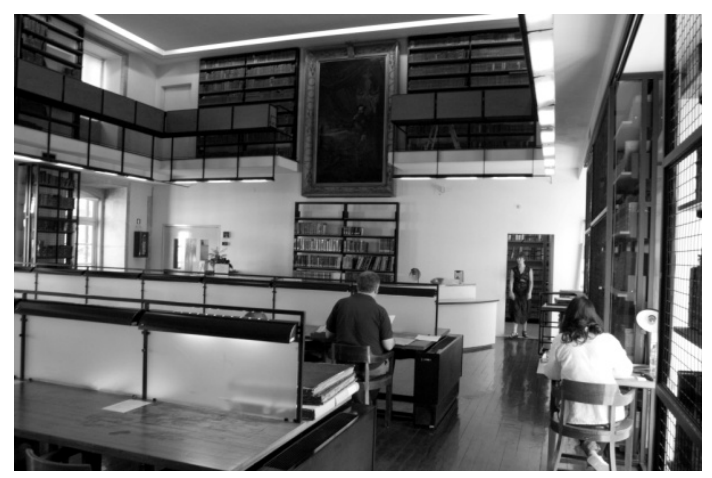

Figure 9: General reading room in S. Lázaro (RSC)

João Carreira, born in 1956, was commissioned to renovate the general reading room. Reverently alluding to the awareness of being inside a Baroque convent, he stressed how that influenced the project which he developed between 1984 and 1985. "Absolutely no guidelines" or concepts were provided, just functional requirements, chiefly the need to enclose stacks and to control temperature and humidity. Keeping artificial lighting at low levels, against the electrical engineer's opinion, was his personal concern "this is a library, not a factory!" Each table is provided with an individual lamp.

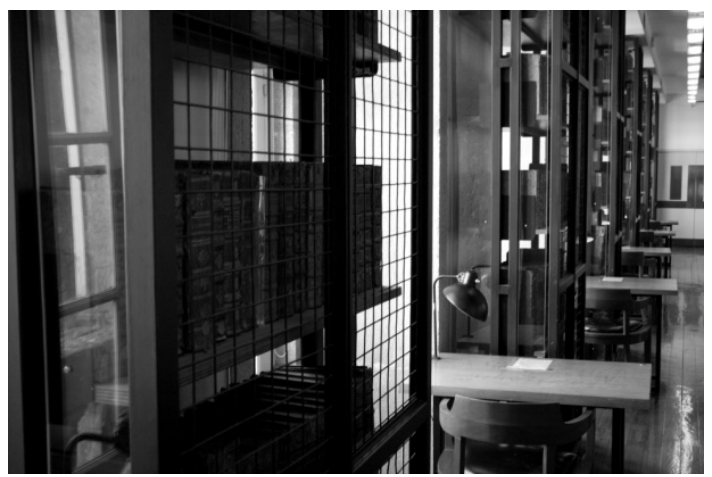

Figure 10: Stacks with old books protected by wire (RSC) 
Faced with the demand to maximize the use of wall surfaces to display old, untreated books in a room with multiple openings, the idea of using an "almost obsessive" repetitive modular approach to the design, "as in Borges' Babel library", came to Carreira's mind. Dimensions were determined by the need to have "modules fitting almost every circumstance" - stacks, lamps and a need to conceal the $\mathrm{HVAC}^{4}$ system. The stack structures are made of black metal, shelves are made of semi-dark wood, enclosed by black wire panels. The same materials were used for tables and chairs. A new mezzanine was designed and the original wrought iron staircase was renovated. A majestic oil painting of Pedro IV, in military uniform, hangs on the wall behind the attendant's desk.

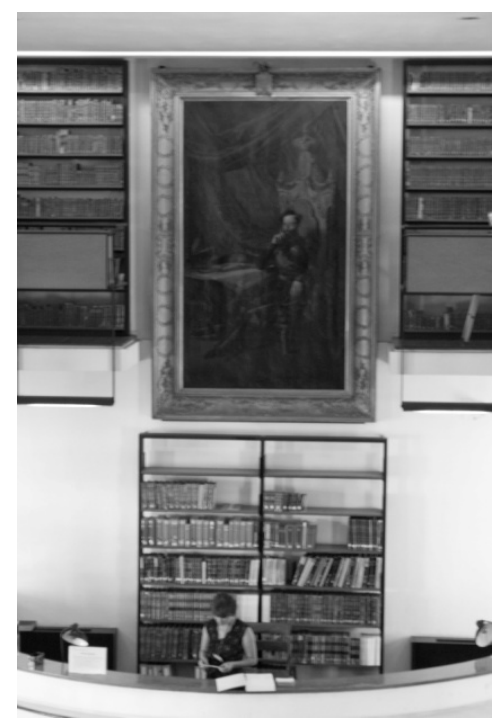

Figure 11: Pedro IV's portrait (RSC)

Seating for 124 people is arranged in rows facing each other. Frontal and lateral shields of opaque glass divide the long tables into various individual sections. Since the closing of the serials room, some of the lateral shields were recently removed to accommodate large-sized volumes such as bound newspapers. Individual tables are available on each side, lining both façades. Some have wired Internet connection.

When entering the room, readers must hand in forms for the documents they wish to use, having written them up in the catalog room. They sign-in in a registry book and are assigned a seat by an attendant. The completed forms are passed on to the deposits section, the documents are sent up by elevator and then delivered some minutes later to the reader who is seated at a table.

4 HVAC - Heating, Ventilation and Air Conditioning 
Although he was criticized by the management for not providing more privacy, the architect did not wish to place people in "horse boxes", allowing instead for some proximity between the readers. Although not explicitly required, Carreira argued, that as a public space, the library should be comfortable to use.

Souto de Moura was born in 1952. His office authored the project to renovate the children's library, the auditorium and its adjacent bathroom. These were completed in 2001. An architect and a technician from that team were interviewed. For this intervention, shelving space was the primary concern of the managers, "the fundamental premise was 20,000 linear meters for stacks". Even the auditorium's walls are covered with closed shelves. But, it must be noted that reverence to heritage and control were implicit in the architects' discourse about the project and were clearly imprinted on the final result. International standards for archiving were also considered.

There are 30 seats in the small children's room for when schools visit the library. Guided visits to the entire library may be provided for them. Closed on Sundays, it is unoccupied most of the time. Shelves cover most of the wall surface. The room may be accessed directly by a near door in a lateral façade. There is a plan to use it to separate children from adult visitors.

Another interesting room is the one for rare documents. It has antique tables, 13 chairs and several enclosed bookcases against the walls. Readers are escorted to it by staff and requested rare documents are sent to the reader from the stack area. A staff member is always in attendance.

Special services are provided for the blind or those who are unable to hold books in the recording booths of the audio library. Professional and volunteer readers do the recordings for the audio books. Aural substitutes for novels or handbooks are regularly produced and sent by mail. On-demand recordings are accepted mainly from persons who are students. Readers who need special services are located all over the country and abroad. Holdings include some 7,000 analogue and 380 digital recordings.

\section{Almeida Garrett}

José Manuel Soares, AG's architect, was given two main conceptual guidelines by the town's Councilor for Culture:

1. "[A] library for those who don't have books, for who's going to have a first contact"; and,

2. Somewhere for students to work or someplace where someone who just wishes to read a newspaper can sit and read. This is to be somewhere that has "continuity with the public space", "as if inside a supermarket, entering or leaving easily". 


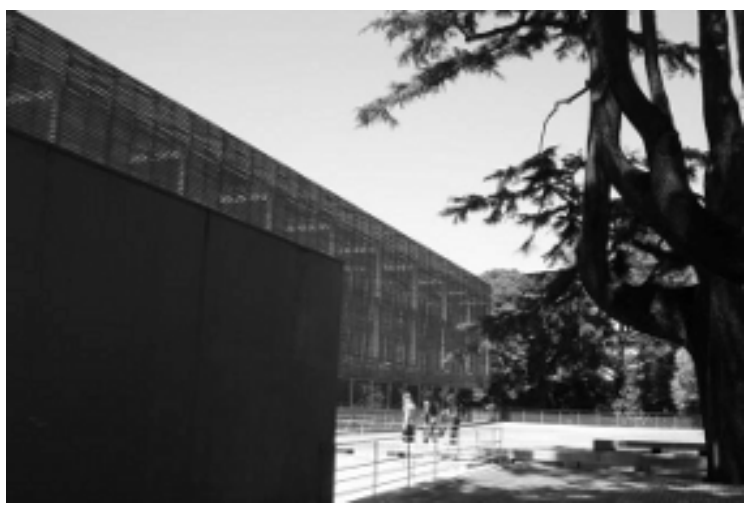

Figure 12: Main façade with log curtain (EL)

A collaborative team was created, which included Soares, the Councilor for Culture and the local Chief Librarian. The team received full the co-operation of the supervising organization - the Book and Libraries Institute. The budget was comfortable enough to allow for experimentation - the wooden curtain being an application of research which had been conducted by engineers from the University of Porto - and for noble materials - such as the large white marble flags and filtering glass. Born in 1953, Soares stressed the kind of teaching he received at the Porto School of Architecture where he was a student just after the 1974 revolution:

"a fundamental thing, a humanistic ability, an ability to generalize and integrate, things that nowadays ... social [and] political concerns, mixed with ethics and aesthetics, practicing ...".

To preserve some huge, ancient trees, a straight-line entrance was not created. Instead, the existing waving path through the garden was used. After crossing the park's iron entrance gates, visitors must take one of the paths that go around the lake and statues. These statutes are allegories of the four seasons (Figure 4). One also walks past huge araucarias, ginkgoes, magnolias and lawns before reaching the building which is hidden behind a curtain of logs.

"Unlike a shopping-mall" or a large supermarket where people feel frequently disoriented, a sense of orientation was planned. The relation with the city gets "known by heart", although one can get some glimpses of the neighborhood through some windows in the back façade (Figure 5). In public libraries, readers "need small spaces, more than large ones" so as "not to get dispersed". A good place is not where everything is, rather it is "where we may have our own secluded spots", which "has to do more with atmosphere quality than with drawing", "a variety within ... great unity", those "physical qualities of space that may be appropriated". The project sought to reach "an architec- 
ture for this specific case", in "a binomial relation" of openness and enclosure. Which evokes Eigenbrodt's requirements for "communication, access, orientation and freedom of movement" when "designing library facilities for everyone" (2008).

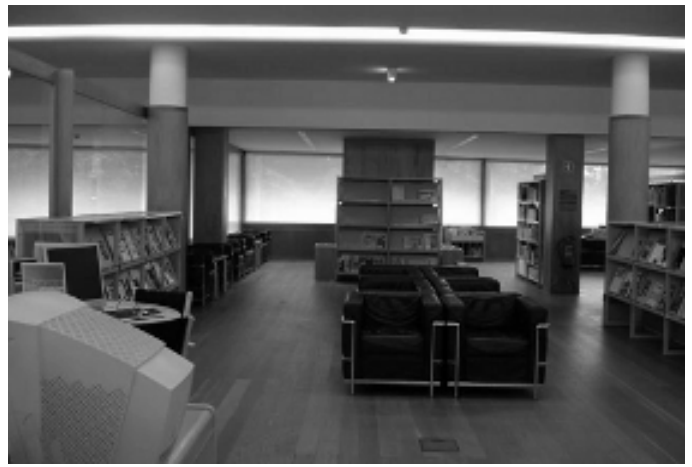

Figure 13: Acesso+ (left) and serials areas (EL)

Soares conceptually based his design on the "basic idea [... of the] Jesuit church": the "nave as a collective space, with a common roof. Lateral chapels for individuality, calmness [and] more spaces". "And there are transversal relations and longitudinal relations among them". "But quite differently form a religious space, isolated, directed" - a cathedral is "centripetal" - "this [...] is clearly a debatable space". Spaces that "have to be relatively neutral, [...] so that they may be adapted to different philosophies that get to change, even with time".

Soares states that he tried to use "the hierarchy [of spaces ...] from a strategic point of view" creating zones with decreasing levels of noise to facilitate increased concentration, as entrants progress, with a "relation among passage and [...] still spaces", not disregarding security issues, but allowing for a global visualization. His intention was to avoid the conventional connotation of floor height with status. Questioned whether flexibility was also in the building's program, he answered: "Indirectly! Space and stability are fundamental things in such a space. There are always people passing through spaces we wouldn't want them to".

The lobby consists of two levels. A white marble staircase leads down to the reception desk and the lockers. The facing wall is painted in a contrasting dark pink. A large auditorium is on the left, ahead is a corridor leading to the cafeteria and toilets. The library's reading spaces are situated on the right. The top level is occupied by an art gallery. An elevator is available for public use to all levels except to the basement, where technical services and the garage are located. To the right of the stairs is a tree-like wooden sculpture, rising from floor to top, visually it unifies the two levels. 


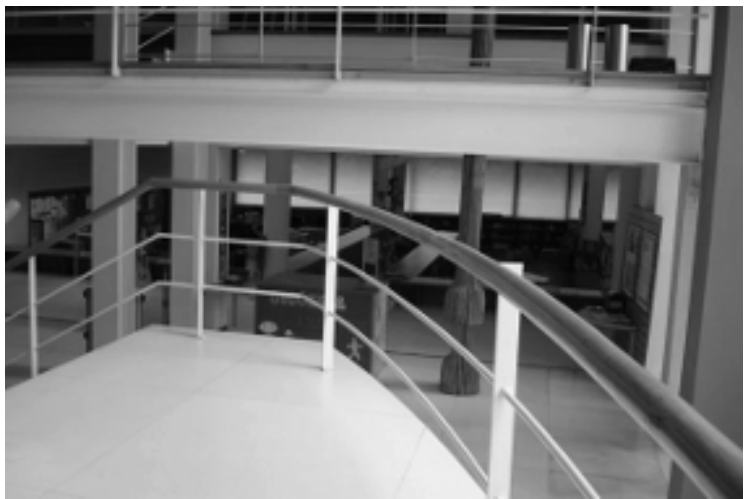

Figure 14: Lobby, the tree-like sculpture at the back (EL)

On leaving the lobby, the floor is covered with light wooden boards. The same type of wood is used for the furniture and stacks. The glass walls display colors, shapes and movement in the surrounding garden or the city. The few blank walls to the left are painted white. The ceiling has a wavy surface which also serves as an acoustic improvement.

Nearest to the stairs is the Children's Area which is at a slightly lower floor level. Access is provided by a ramp. Waist-high stacks, cubes for albums, small tables, 74 chairs, some computers and cushions are in this area. Rectangular tables are arranged in sets of four and larger round tables are placed along the sides. A few tables have a laminate coating for manual activities. A small room has been provided for Story Hour reading aloud.

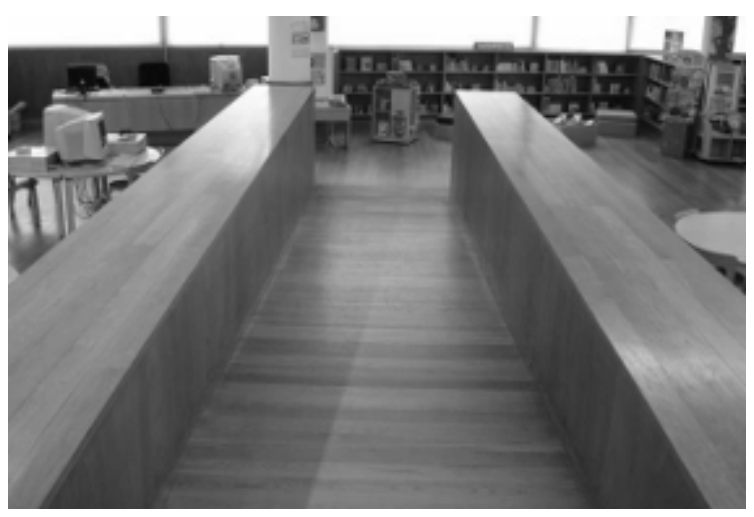

Figure 15: Ramp to the children's area (EL)

Along the main façade, a corridor leads to the adults reading area which has 130 seats. A central mezzanine, which creates a void like that of a large well, allows one to see down to the lower level. The multimedia area with several 
computers, TV sets, round tables and sofas with seating for 28 is found in this section. The Internet may be accessed from 20 points and Wi-Fi is available all over the building and in the garden. A collection of 63,500 titles may be searched in an online catalog. A workstation dedicated to the blind and amblyopic (Acesso + ) is at the entrance to the adult's area.

Covering an interior wall of the mezzanine and stretching down two levels is a portrait of Almeida Garrett, the romantic writer after whom the library is named. Its watercolor-like paint strokes and imprecise traits portray a phantomlike impression rather than a realistic image. The painting is neither monumental nor authoritarian.

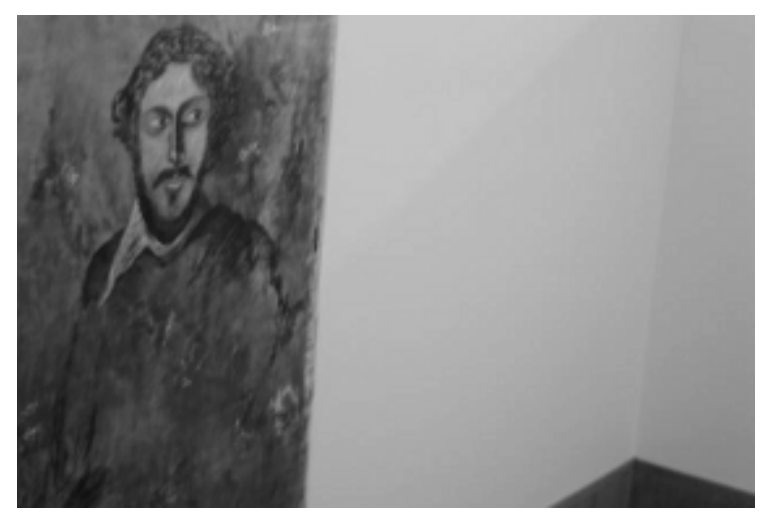

Figure 16: Garrett's portrait (EL)

A glass panel was later added to soundproof the noise from the children's area. A complete visual perception of the whole, almost an open space, is facilitated. While seated in the cafeteria, people accompanying children may watch them in the Story Hour room through the glass panels in the walls of the patio.

Reading tables are placed in different configurations in the adult area, in pairs by the windows, in rows at the end of the reading area by the lateral façade, in a larger group in the Internet area; chairs line the mezzanine's counter. Stacks located around the floor provide some privacy and they also serve as a means of controlling noise flows. Some stacks are placed against walls.

\section{Space Appropriated}

\section{General traits}

Readers rated AG's building very positively with comments such as "well achieved", "wide", "with [...] no obstacles", "all very pleasant", "cozy" and "one of the best things Porto has". Other comments included "full of light" and "transparency" suggesting a hypallage - the transference of a quality from physical conditions to the emotional ambiance of openness and tranquility. 
Only a female reader, living in a therapeutic community commented negatively when she said "a true rigidity, $[\ldots]$ this building restrains ... I was the one who had to adapt". This could perhaps be a reflection of her uneasiness of be-ing in a public space. Luminosity and transparency are, in the view of the authors, a translation into architectural language, of the concepts of free access and circulation which under laid the library's program.

It should be noted, however, that readers attach more importance to the quality of services, and above all to staff attention and support, rather than to comfort or aesthetic features in both libraries, at least at a conscious level. But, at SL, no particular ambiance feature was emphasized, positive or negatively, apart from some mention of quietness. With medium to low occupation rates, one frequent newspaper reader preferred SL to AG's corresponding crowded area where he has to wait for his turn. Being "a building of importance" was the only aspect some emphasized, showing readers felt privileged to use SL's library.

One negative statement was made about the deficient lighting in SL's general reading room and about low temperatures in winter. Some users found the chairs in the general reading room uncomfortable. Homeless or poorly housed readers were much less demanding with regard to their comfort levels. In the authors' view this is a reflection of their class patterns. SL's special rooms also drew comment. Among the issues commented on were that some children felt frustrated in not being able to reach books on high shelves without adult help; a researcher felt constrained for being the only person occupying the attendant's whole work-time in the rare documents room; frustration was also expressed by a reader who had been told, he stated, that special qualifications were required to access rare documents; persons wishing to have free-access to shelves in all rooms, including those behind wires in the general reading room also expressed frustration. Complaints about document delivery delays in the general reading room appeared to be triggered more by this mediated access and lack of autonomy rather than by the time it took to access documents. On their own it is likely that readers would probably take longer to retrieve documents, than having the documents brought to them.

It should also be noted that the sectionalized architectural treatment given to different areas not only reflects, but also reinforces, the departmentalized organization of SL. This approach is even denoted in nomenclature: the word "area" is used for "library", as in the children's library or the audio library, as if they were separate institutions. Apparently, scholars and researchers feel more "at home" than other readers. Public reading, for leisure or study, has been patched in an ambiguous coexistence into an institution which has heritage and conservation goals. The superiority of the pristine mission often surfaced during managerial discourse (Passos 2010).

Silence in the library is a frequently addressed theme in the literature (Bertrand 1994; Finlayson 2008; Miribel 2007; Mattern 2007) although empiri- 
cally-based research is scarce. Noise was not an issue in either library. Several readers, mainly younger ones, even stated that they preferred to hear a soft murmur over absolute silence. Cell phones ringing are the main cause of occasional complaints at $\mathrm{AG}$, while high heels tapping on the floor caused some discomfort in SL. Bertrand (1994) remarks that noise is, along with architectural and regulations devices, most efficiently regulated by social control, and that social class is an important point of reference, as demonstrated by the fact that popular sections are noisier that erudite ones. Mattern observes that "both enforced silence and freedom from noise represent forms of power", associated with habitus (Bourdieu 1985), the socially learned, embodied predispositions that shape behavior.

But, and contrary to the major cliché and anecdotal theme (Sequeiros 2011) users, especially the most frequent ones and not the librarians, were the ones pressing for a quiet atmosphere in AG. A tacit code of conduct, a form of relational contract (Certeau 1984) is enacted, while no formal regulation is in place to regulate noise production. In particular, it should be noted that complaints about noncompliance (with respect to keeping noise levels low) had more to do with the ability to embody the adequate attitude, or the "estimated legitimate practices" (Bourdieu and Darbel 1966), than with noise production. This is how noise production should then be understood: as being deeply associated with behavior that is labeled as inappropriate or being out of one's place or milieu, rather than being simply associated with physical and aural dimensions. As there are sensory, aesthetic, social and affective interrelated facets associated with this issue, the concept of a collectively woven reading atmosphere was proposed (Sequeiros 2011).

Reading is an "ubiquity" exercise, an "absent impertinence" (Rosolato qtd. in Certeau 1984), inserting a personal space into the physical one, and the rules of silent reading in public are to be learned and embodied from an early age. Additionally, reading in public requires concessions over a personally reserved space, as many readers in AG stated. "After half an hour of reading, I'm not here, and that is very motivating, interesting and useful to me" (blind reader, aged 58). Similarly, aural technology - MP3 or CD players in portable computers - is used by many, especially students, in AG, to reinforce privacy and create an extra, superimposed space (Bull 2006). The use of earphones also signals a wish not to be disturbed. This more relaxed form of work was not observed in SL where students are not so frequently seen, except if looking for old documents.

AG is quite accessible for persons with physical disabilities. In SL, both the visually and locomotion disabled need to be guided. SL's sound library users usually use their home's space for reading. By using these materials at home and not having to travel to the library these users are saved from negotiating obstacles in the city during any journey to the library. This personal, aural space provided by auditory reading - sound recordings reading, as opposed to 
Braille reading - also has its own quality criteria: it should not be impeded by over-interpretation, according to a more demanding reader: "I think I'm entitled to be the one to interpret the text, and not to get an idea compromised by, say, the idea the speaker has on the work", "I'm very much an adept of an open reading" (blind reader, aged 58). Adaptability in aural space, just as in architectural space, is appreciated.

With no Wi-Fi, or a fully automated catalog, some library patrons admitted that they went to SL for its unique collection only and that they would prefer to go somewhere else, should an alternative be available, even if it meant travelling to another city. Frequent complaints were heard about the price of and delays associated with digitization services. A reader also suggested that photographing old documents should be allowed. A strong and regular criticism concerned the need to consult several catalogs to find items. This took a lot of time and often resulted in one overlooking important works. It was often impossible to overcome this barrier without assistance from the staff. Despite these challenges, the staff was given a positive assessment by readers.

There was considerable variance in how different areas interacted (i.e. the reading room, the cafeteria and the auditoriums) in the two libraries. Nevertheless, and in spite of the functional difficulties, this area interaction should be encouraged through collective reading and debate, spontaneous or programmed community events and through workshops ((book) binding, editing, reading aloud, theatre, writing, researching, knowledge banks ${ }^{5}$, the Internet). Users might be involved in the proposal of ideas for activities and in their implementation. An example of a good idea - yet simple to implement - occurred during the summer of 2010 when small bookcases were placed near to the benches in the patio of SL. The books in these cases covered a variety of topics such as "Detective Stories", "Comics" and "Travel". These books became the focus of much borrowing, which would likely not have happened had these books remained dormant in their usual space.

\section{A Place for Emotions}

References to AG's openness have already been mentioned: tranquility, organization and the ability to concentrate were singled out as valued traits. Students also referred to a feeling of togetherness (Bakardjieva 2004) a form of "intrinsic order" (female student, aged 40) stimulating concentration: "all the other people are also doing the same as I am, so [this is useful] to soften things a little [laughing] if it's something I don't like to do" (male student, 34 years old). In SL, secondary school or undergraduate students are not very common, and readers do not have the opportunity to observe each other easily because of the enclosed spaces and rooms. As a consequence, neither togetherness nor other affective atmospheres are likely to emerge and, actually, no reference 
was made about either of these traits. While the construction of those atmospheres was a clear process in AG, personalization in SL appeared difficult to achieve. Affective qualification did not stand out, reflecting personal noninvolvement, and merely utilitarian appropriations seemed to develop. Contrary to the criticism made to the architect, users may be too isolated, especially in the general reading room.

Being a reader may also be seen as a personal achievement to overcome barriers, as was the case of a blind woman in AG, the daughter of manual workers who worked hard to gain her education. Or, the Cape-Verdean emigrant woman, 43, who holding a "slave job", "much sacrifice, little gain", "shut my mouth because I needed it", turned into "a victim of [her] own situation"; but she "didn't lose courage", pursuing another opportunity is "something to be proud [of]". Returning to school to complete 6th grade, unable to afford a computer, she feels happy to be able to use AG's free access PCs to do her homework.

\section{Personalization, Privacy, Surveillance}

The characteristics of spaces may be determinant in the processes of appropriation by users. While in SL no special case of space appropriation was observed, in AG some interesting ones were noted: the counter in the mezzanine was waist-level high and had removable shelves. However, in order to create a working area, readers removed the shelves, found some chairs and used the mezzanine counter as a workspace (Figure 17). Management accepted the appropriation of the space in this way and presently this space, for the public, is one of the most coveted work areas in the library.

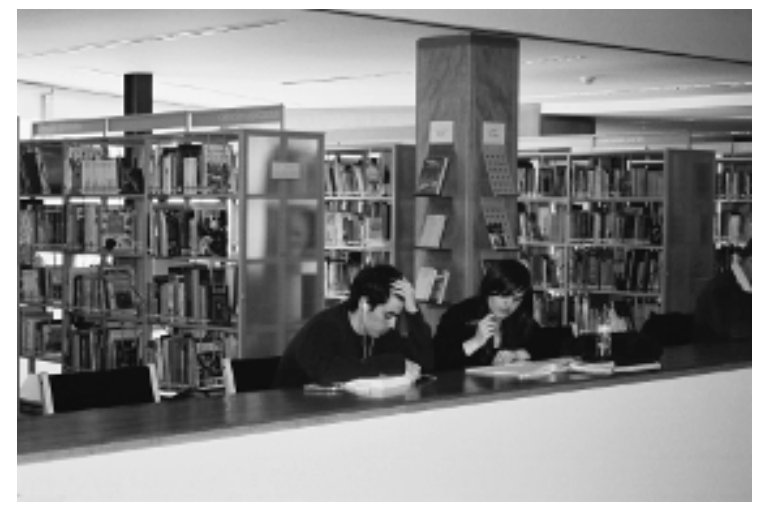

Figure 17: Mezzanine appropriated as a work area

Other forms of space appropriation and tactics for place-making were observed in AG. Children are allowed to bring in toys and drawing materials, some tables have special coverings for these activities; a basin is nearby in 
case hands need to be washed. Additional space is sometimes created and reserved by readers, particularly students, through the tricks of a silent competition scattering personal objects on adjacent tables signal that company is unwanted (Certeau 1984). Contrary to SL, students at AG have a natural and welcome presence, which sometimes is predominating in this interior landscape. Most likely their serious occupational status legitimizes their behavior, for example, when they take the initiative to require silence in their vicinity.

The variation in privacy requirements is seemingly tied to gender, social class and housing conditions: a young woman reported uneasiness for being stared at "by men in an unpleasant way"; the homeless reader did not mind if others peeped at his PC screen; a young couple with two babies living in a single room of a social-housing apartment with twelve relatives, laughed out loud at our question about a possible lack of privacy: the library was the only place where they had some degree of privacy compared to what they were accustomed (all AG cases). "The absence of intimacy is perhaps the best poverty indicator, even more than income", Petit (2001) notes. "I need my private space and live amid a lot of people" (woman, living in a therapeutic community, 40 years old); to her, reading in AG "means finding the words for things, resting and reflecting ... [and it is] very pleasurable". She further said "If I stopped leading the life I'm used to in public spaces, I would certainly lose a true pleasure and [the] real harmony I'm looking for."

Unlike in SL, in AG the use of lockers is not compulsory and they remain mostly unused. Portable PCs may be made secure by lock chain cables which can be borrowed as there had been thefts in the past. Both libraries have antitheft antennas installed. In AG, the presence of security guards and cameras the latter unnoticed by users as a rule - was positively valued. The most socially or physically fragile - the man using crutches, the homeless person, the African immigrant - appreciated the security measures the most. AG is sensed as a safe space. In SL, however, the absence of guards was criticized by attendants who were assaulted by readers who had been caught stealing. Table surfaces in SL's general reading room showed evidence of having been scratched on several occasions and the bathroom walls were also marked. Such behavior was not noticed in AG. One is forced to ask, does this happen in SL in spite of a more rigid atmosphere - or precisely because of it?

In SL readers tend not to use the Internet stations with screens that face the entry as they are too exposed. In AG Internet stations are better placed.

\section{Conviviality}

Reading may not be as solitary a pursuit as it seems: in AG children are usually accompanied by relatives or teachers, adolescents and young adults enter in pairs or groups; recognizing familiar faces and "pleasant gazes" from regular readers (retired male reader) is appreciated. A library may be a place for conviviality. Loners also seem to find a library a pleasurable place as there are 
many such persons there. Proximity without propinquity, in Park's expression (qtd. in Tonkiss 2005), is frequently sought in urban centers. "Above all, I like coming here a lot when I'm feeling down, I come in and it seems I reinvigorate! I cross that door and seems like home to me, as if it was my own family, I feel superbly well!" (homeless, former typographer, 34 years old). Readers tend to visit SL unaccompanied. Most seats in the general reading room are isolated by opaque glass shields. Relaxed interaction among readers was not observed there, while it occurred frequently in AG.

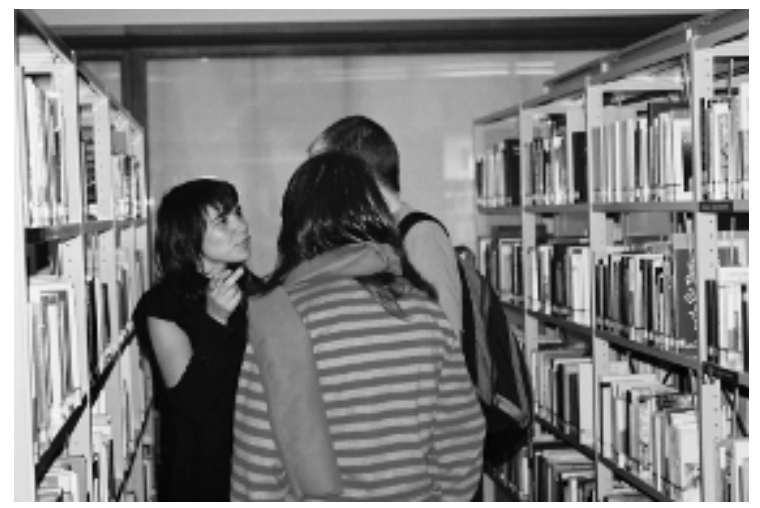

Figure 18: Having a chat between the stacks

Meeting socially diverse people seems to be appreciated, elderly people like watching young ones and children, the homeless reader declared that he enjoyed the social and age diversity, while watching "different faces every day". And so, the planned separation of children from adults, even if only in the common circulating areas, may be a bad idea for SL.

Conviviality, alongside with gratuity, was one main motivator for visits, according to some of the persons who were interviewed.

Given and Leckie (2003), in research on public libraries in Canada, stress that talking is one of the most common activities - "libraries may need to do more to encourage the view of [the] 'library as interactive place' versus [the] 'library as quiet space"".

The central role of libraries to promote conviviality in public spaces has been evoked in literature (Given and Leckie 2003; Leckie 2004; Audunson 2005; Illich 2005 [1971]; Audunson et al. 2007; Fisher et al. 2007; Aabø, Audunson and Vårheim 2010). The fact that libraries are places that are unassociated with consumption was stressed (Leckie and Hopkins 2002). Aabø, Audunson and Vårheim found, in two Norwegian libraries, that those who were in the low-income bracket exhibited this behavioral trait more than those who earned high-incomes (2010). Several researchers have found that in times of economic recession libraries tend to have more use because they are public 
and free resources (Laidler 2008; Oblander 2008; Lizdas 2009; Bertot et al. 2009; ALA 2010).

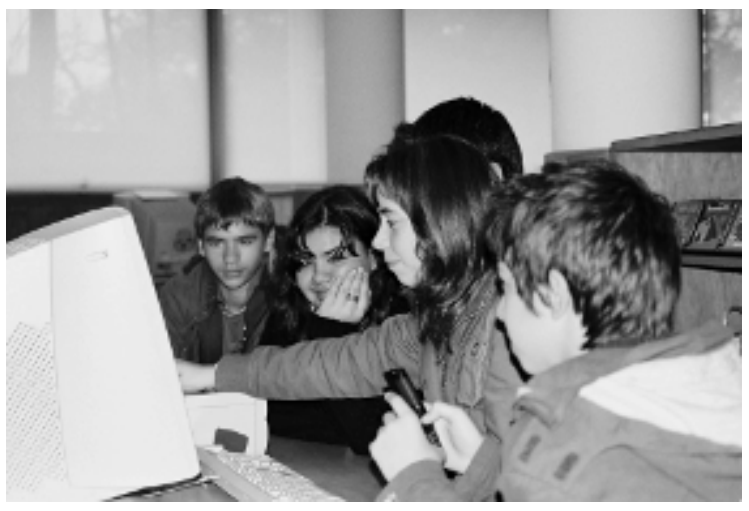

Figure 19: Informal group of pre-teen visitors

Furthermore, and in association with industrialization, technological changes and the urbanalization of urban and suburban space (Muñoz 2008), there has been a loss of inhabiting and living know-how (Cérézuelle 2007), in both the everyday use of private and public spaces. In urban and especially suburban environments, space is becoming undifferentiated and homogenized. The hypermarket, the church, the memorial monument, the sports centre and the library all spaces turn out to be confused with one another. Library use may contribute to recreate and update this lost traditional wisdom on inhabiting. To achieve this, it is proposed that people must be given a chance to learn how to inhabit by inhabiting.

\section{Public Space}

Readers perceive libraries as places where public services are offered. This was particularly clear in AG, where openness and social diversity were also frequently pointed out as characteristics of such spaces, both by readers and staff. Several readers conceived a similarity between libraries and other public services, such as health services. In SL, the representations of public service were more tied to accessing ancient, rare documents or to using a heritage building. Being open to all was negatively viewed by some members of the staff, once they associated such open access to the occasional aggressive behavior that has already been discussed.

New power relations between public and private have been rendering public space increasingly less public; if access to public space cannot be prevented, it can still be devalued and made less civic through a culture of consumption (Pirodi 2002). Taipale analyzes the pluridimensionality of public space, which in- 
cludes time, media, ICT and politics. He stresses that to be fully understandable "socio-economic and power-driven characteristics of each one of these layers of public space" should be analyzed (2006). As Naomi Klein (2003) insightfully puts it or the library as space has distinctive values: "knowledge (as opposed to mere information gathering); public space (as opposed to commercial or private space) and sharing (as opposed to buying and selling)". Threatened by profit, privatization and corporate globalization, libraries should devote themselves to connectedness and openness by resisting privatization, by conversing with their communities, being transparent and, when possible, being democratic.

Libraries may also be considered as a prototype of an "open institution" (Illich 2005) by facilitating human activities and the creation of new relationships among people and their surroundings, which constitute the true sources of education. In the context of an increasing commodification of diverse aspects of life, providing a public place for reading, knowledge dissemination and encounter among peers is also a contribution to The Commons ${ }^{6}$ by investing them with physical and symbolic content (ibid).

Just a few readers in AG declared to debate with others about what they had been reading, although there was interest in discussing two interesting topics: a recent report in the newspapers about an increase in the price of bread; and, a search for information on a municipal market which was due to be converted into a shopping-centre. This proposal had been the cause of protests. In SL, no similar cases were observed.

Libraries as places for fostering the Habermasian public sphere of opinion and sustaining debate is advanced by Alstad and Curry (2003), who propose a set of measures to implement the use of libraries in a way that they become a part of the "sphere of non-governmental opinion-making" (Habermas 1998). Buschman elaborates on why the concept fits into library reading (2008). He claims that libraries "house and further rational discourse through the organization of collections coupled with the principle of unfettered information access". Also that libraries enact "the principle of critique and rational argumentation" through the "balanced collection", preservation and "furthering inclusion" through "intellectual diversity". Libraries allow for the "verification of claims to authority" and so create a basis for intellectual debate. Buschman finally stated that the policies and practices of libraries "make access to information and education more widely and universally available".

The field enacts the principle of critique and rational argumentation through the commitment to balanced collections, preserving them over time,

6 The Commons are resources shared and cared for within a community. They may include natural elements such as water or grazing land, or cultural goods, such as music and art and public goods. Public libraries may fit into these last two categories. 
and furthering inclusions through active attempts to make collections and resources reflect historical and current intellectual diversity.

Eigenbrodt associates the realization of these objectives with informational participation (2008a). As a public service, under the scrutiny of public opinion for ethical issues, libraries may provide an important area for this public sphere, especially if a participatory approach is developed, according to Fraser's view (1992). Such an arena, not restricted to opinion but also directed to "formation and enactment for social identities", fosters decision-making thus allowing for "strong publics" to emerge.

\section{Differences and Inequalities}

Not surprisingly, the most economically fragile were the persons who stressed the advantages of a public free service. They expressed concern over the privatization wave that was invading the country. But they also appeared particularly well positioned to reflect upon multiple issues, coming from the "vantage points of the subjugated" (Haraway 1988).

One retired female user in AG admittedly resented the presence of "those social exceptions" - homeless readers - under the unconfirmed pretext that they produced "lots of noise". On the other hand, another declared:

"sometimes there are some people here who don't know how 'to be'
[in such a place], well, we know that it's the same everywhere, but
then you forgive them, you accept them, they also have the right to be
here ..." (a male retired reader in AG, 72, a former bank clerk).

Some members of staff declared that the homeless sometimes got into arguments over which films to watch on the TV sets. This led to the removal of one of the sets. These persons were also said to use the sofas for sleeping and the bathrooms for their personal hygiene; during this research several persons were observed taking a nap, mostly after lunch and no one woke them up. In $\mathrm{AG}$, an often told story concerned a conflict involving a gun and eastern immigrants, proved to be nothing more than an urban myth. As urban figures, the homeless may serve as scapegoats for subjective insecurity feelings of others. This tends to amplify any real insecurity situations that may exist (Fernandes 2003).

The only homeless person who was observed in SL did not use the reading rooms, he just went into the library for the cheaper coffee that was available in the atrium's vending machine or to use the toilets - the park has none. In AG, some individuals, known to be sex workers were observed using that library. Their status was identified by staff who had previously worked in SL. However. they did not use that neighboring library (SL). While in AG "marginal" readers are tolerated, although not openly accepted, in SL their presence ap- 
pears to be more overtly disapproved. Whether this has to do with the imposing nature of the building, verbal admonishments, social or corporal hexis is a matter for further research.

In terms of social class, most libraries in Portugal (Freitas, Casanova and Alves 1997; Fortuna et al. 1999) are predominantly used by students, intellectuals or skilled professionals. Manual work is not even listed in the classification of jobs used to register readers in the libraries in which this research was conducted. Among the interviewees, there were almost no manual, unskilled workers and there were none from the upper-class.

Frequency of use seems balanced between the sexes in AG; however, in SL, male visitors are slightly more in number. An assumption that libraries are feminized spaces was not supported by the observation and usage statistics were not provided for this research. There is the possibility that males may outnumber females as registered readers, but not as visitors. On the contrary, a clear gender imbalance was perceived among middle-aged and elderly women and their literacy rate is known to be lower than that of their male peers. In spite of their lower literacy rates, the almost complete absence of women in these age groups from the library is very likely due to their domestic responsibilities and women are known to have less time for leisure. It can also be said that SL has fewer young visitors, leading in general, to less social diversity.

Secondary school or undergraduate students may not feel welcome in SL, and this is probably more due to their status than their age: "a bunch of young people, [the staff] gets a bad impression from us. By the looks! Although we're students" (shared opinion in a group of three, 18 to 20 year-old boys). Informal conversations with other young students and an architect produced similar impressions. Researchers, on the other hand, are treated warmly, which is in keeping with the staff's representation of this library as being a place of heritage. Evidence of ethnic segregation was not apparent nor reported during interviews. Accessibility to SL's facilities requires improvement. On the other hand, its audio library has pioneered a quality service which is also provided to readers living abroad.

7 Bodily hexis is a type of disposition, "a basic dimension of the sense of social orientation, is a practical way of experiencing and expressing one's own sense of social value. One's relationship to the social world and to one's proper place in it is never more clearly expressed than in the space and time one feels entitled to take from others; more precisely, in the space one claims with one's body in physical space, through a bearing and gestures that are selfassured or reserved, expansive or constricted ('presence' or 'insignificance') and with one's speech in time, through the interaction time one appropriates and the self-assured or aggressive, careless or unconscious way one appropriates it" (Bourdieu 1979). 


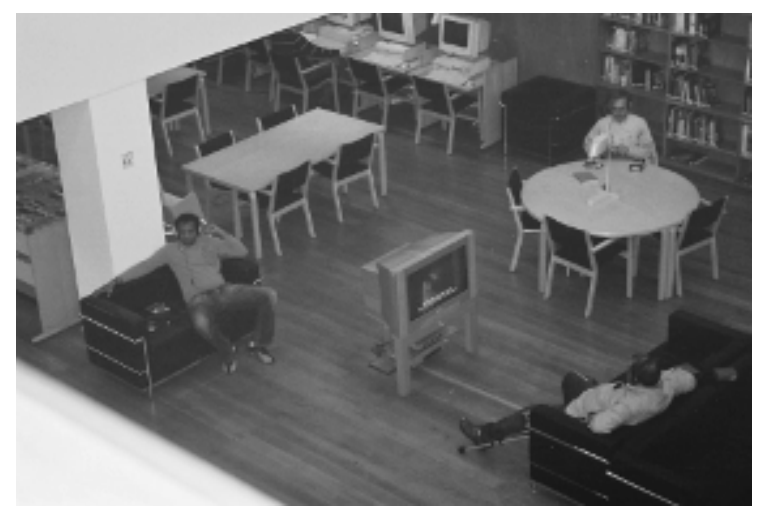

Figure 20: Multimedia area, relaxed postures

In AG, a hierarchy of spaces really emerged, not tied to floors but to documents physical support for example, less educated readers preferred the multimedia area: "upstairs is more for reading, down here is more for leisure, to be more relaxed" (immigrant truck driver of African ethnicity in his 40's). Body postures may be clear markers of a corporal hexis associated with social class (Bourdieu 1985). One easily observes that attitudes in this space are much more relaxed.

\section{Public Reader Profiles}

As a way of shedding light on reader's practices, their use and appropriation of library resources and space, the relationships they create with others while reading, data was collected and interpreted through a mix of tools: ethnographic observation, in depth interviews, photography and children's drawings. Common traits emerged and readers were grouped into different profiles. This same methodology was used in SL (Sequeiros 2010). While researching AG's insertion within a garden, the suggestive power of metaphors (Haraway 1988) as a way of adding meaning to the collected information emerged.

\section{Bees}

The aim of Occupational users or bees is to keep busy in useful ways, benefitting from an ambiance that encourages study and the availability of free resources - "The day goes by more quickly, it's more productive" (female, 28, unemployed, AG). They search for precise topics or apply for jobs; they have organized schedules, even if they are unemployed, they are working in the library. Their vocabulary avoids words such as unemployed or retired, an alternative work ethic seems to frame their practices. Being highly qualified, a main 
motivator for visits to the library is Internet use. Some of these readers bring their laptops and wear earphones. Another frequent motivation for persons in this group is to read the newspaper. They use table surfaces to read and write as well as to use their laptops and usually they seek a space near to a power supply. In AG, they scatter personal belongings on the tables. In SL, if they are regular users, they will probably ask for a specific table in the general reading room instead of an assigned one. The regions (Certeau 1984) they use are similar to those used by students and scholars.

Ants

The Student users, or ants come to the library frequently in groups or pairs, mostly after lunch. Some are still studying for their undergraduate degrees while others are writing their Master's theses. Their ages range from twenty to the late thirties. In AG, the togetherness that is facilitated by the library which attracts them. Their use of library resources is mainly instrumental, that is basic, tied to the instrumental use of information resources. They usually bring their handbooks and on occasion their laptops. Mobile audio may be used to enhance privacy. The library's bibliographic resources, unrelated to study, are not used by persons in this group. They prefer to use individual tables and Internet access points. They sometimes use tricks to create extra space. Usually they produce some background noise which they prefer to work with visà-vis complete silence. In SL, as previously reported, students are not often seen unless they are researching the old collection.

Owls

The Scholar readers, or owls devote their time to researching topics of their choice, very likely Local History. They are informal learners, study autonomously and they have flexible calendars. They are likely to be men who are retired and frequent users of the library. Although they are not many in number, they keep their presence discrete. Their activities were mainly note-taking and writing essays on pads. They are highly regarded by staff. Other library users may follow their activities with curiosity and respect. In both AG and SL, some scholar readers occasionally interact with younger people, for example, some elder readers attentively followed the activities of the younger readers, occasionally spoke to them and offered support.

Cats

The Informed readers, or cats make a point of keeping up with the news by reading newspapers or magazines. The group is almost exclusively male and the elderly predominate. No social interaction with other users or staff was ob- 
served. They tend to be reserved - several declined to be interviewed. Unlike the others, cats tend to stick to their special area. Internet use is an exception. In AG they occupy the press corner sofas, whereas in SL they tend to gather around the first tables in the free-access room. Their attitudes are not as relaxed as that which exists in AG's multimedia area. Sometimes they have to wait their turn to read their favorite titles. They exhibit an instrumental reading mode. Yet, instrumentality may mean something other than just reading: "maybe a few weeks go by and I don't memorize, at my age, I don't feel like wearing out my head any more". In AG, a male reader in his 70 s was of the opinion that reading is good for one along with the exercise that one gets from walking to the library. In SL, a 49 year old male African immigrant who cannot afford to buy a computer also shows a special communicational trait: besides reading periodicals, he uses the Internet to stay in touch with his family in Angola, to read sports news and to attend to several personal matters, from taxes to social security.

\section{Sparrows}

The Recreational readers who were interviewed were mainly children. The exception was an international truck driver who is an African immigrant in his 40s. He uses the multimedia area in AG, which, he feels, is "more for leisure". He used to visit libraries in several European cities where he lived. His free days in between travels are spent at the library where he watches DVDs and YouTube, listens to music, reads magazines and borrows books. They all go to the library mainly for recreational purposes, moving and reading in an unwor-ried fashion.

All the children interviewed in AG, between ages 4 and 8 , are cumulative readers $^{8}$, sometimes meeting friends and joining other children in games, or visiting the library with their teachers. All of these children also have books at home. The garden is also a destination during their visits. They move freely, sometimes they run. The Story Hour room gets crowded during sessions, and as the room's ventilation is not adequate, it was observed that relatives and children eventually used books and papers as fans, but nobody left. Almost all of the children drew computers - some even drew only computers, when asked to depict "what a library is". They sit on chairs or cushions, or just lie on the floor. They know this area has some restrictions: for example they are not allowed to scribble on books nor climb on tables.

\section{Butterflies}

Strolling readers, or butterflies spend their time strolling around with no specific activity in mind, occasionally picking up some item - resembling Wirth's 
(1964) urban strollers. They generally do not interact with others. While walking they glance at newspapers, magazines, records, Internet pages and books. Less qualified than some other groups of library users (secondary school or less), these readers are manual workers, people who are retired and unemployed persons. They cover a range of ages, some are children. Strolling readers mostly use the multimedia area, couches and circulation spaces. The homeless reader comes one or two hours every day, following his street companions advice: "you watch a movie and when you go out you feel quite another person"! This is a closed space where he feels safe, away from those street "complications".

A young couple, both 22, pushing two baby prams also fit into this group as well. Their educational level is below the minimum standard; they live in a single room, in a crowded apartment. They say that they get some privacy in the library. During the observation the mother requested a user card. The plan is for the family (the parents and the two children) to visit the library every Saturday. The parents search for information on baby care, baby games and send SMS's. The mother does not usually read, except stories to her babies. The father prefers to view multimedia items. As a wide, "clean", "ordered", "quiet" space the library is seen as a better space for their family than a cybercafé.

It should be noted that no strolling readers were found in SL. Their departmentalized spatial arrangement and heritage-oriented management does not seem to allow this type of space appropriation.

\section{Residents}

Both libraries have their habitués (regulars), a user subgroup composed mostly of scholars and occupational readers, nicknamed "residents" by the staff. As frequent users, they have favored places, preferring the mezzanine in AG, from where visual control over the whole place is possible; in SL, favorite places are the first round table in the free-access room or the lateral ones in the general reading room. They sometimes use the complaints book, a resource scarcely known to other users.

"This is their second home", "they get accustomed to us and we to them", this is how a very attentive female librarian explains her special connection to this group in AG. Some elder male readers, if they were noticeably absent, may even benefit from her special interest through an inquiry about their health. An anecdotal but, paradoxically meaningful episode was shared with the researchers who were told by the staff that an elderly male reader once knocked at the staff entrance door carrying his own sofa and asked to have it placed beside his usual table.

The frequency and duration of visits, this competition for personal attention, which they feel they are entitled to, all converge to allow the users 


\section{Comparative Table}

\begin{tabular}{|c|c|c|c|}
\hline \multicolumn{2}{|l|}{ Space provided } & SL & $\mathrm{AG}$ \\
\hline \multirow{3}{*}{ basic concepts } & & $\begin{array}{l}\text { implicit: heritage } \\
\text { (architecture and holdings); } \\
\text { control; library as a } \\
\text { „temple of wisdom“? }\end{array}$ & $\begin{array}{l}\text { interactive, open } \\
\text { library }\end{array}$ \\
\hline & & preservation, shelving & $\begin{array}{l}\text { publicness with } \\
\text { diversity }\end{array}$ \\
\hline & & $\begin{array}{l}\text { remediation diachronic } \\
\text { additions } \\
\end{array}$ & unitary project \\
\hline \multirow{5}{*}{$\begin{array}{l}\text { programme } \\
\text { (function) }\end{array}$} & the core is... & $\begin{array}{l}\text { controlled reading rooms } \\
\text { (free-access room as } \\
\text { secondary) }\end{array}$ & free-access \\
\hline & functioning & rigid, highly regulated & lightly regulated \\
\hline & $\begin{array}{l}\text { access of persons and } \\
\text { objects }\end{array}$ & heavily controlled & free access \\
\hline & access to contents & hindered, regulated & easy, direct \\
\hline & $\begin{array}{l}\text { interaction among } \\
\text { areas/people }\end{array}$ & hindered & easy \\
\hline \multirow{9}{*}{ structure } & urban insertion & $\begin{array}{l}\text { no relation library/garden } \\
\text { nor library/neighbourhood }\end{array}$ & $\begin{array}{l}\text { inserted in a public } \\
\text { space (but possibilities } \\
\text { only partially } \\
\text { explored) } \\
\end{array}$ \\
\hline & & $\begin{array}{l}\text { diachronical and } \\
\text { departmental juxtaposition; } \\
\text { 'libraries' inside a library } \\
\text { with diverse design criteria }\end{array}$ & $\begin{array}{l}\text { homogeneous spatial } \\
\text { and constructive } \\
\text { conception; collective } \\
\text { space with } \\
\text { individualized places } \\
\text { offering different } \\
\text { scales and inter- } \\
\text { relations }\end{array}$ \\
\hline & display & fixed & \begin{tabular}{|l|} 
adaptability-flexibility \\
in uses and in time
\end{tabular} \\
\hline & $\begin{array}{l}\text { visibility over whole } \\
\text { space/room }\end{array}$ & no & yes \\
\hline & wi-fi acess & no & yes \\
\hline & $\begin{array}{l}\text { security guards and } \\
\text { cameras }\end{array}$ & no & yes \\
\hline & anti-theft antennas & yes & yes \\
\hline & $\begin{array}{l}\text { mandatory deposit of } \\
\text { personal belongings }\end{array}$ & yes & no \\
\hline & accessibility design & no & yes \\
\hline \multirow{3}{*}{ form } & identities & fragmentary & unitary \\
\hline & $\begin{array}{l}\text { design and materials } \\
\text { according to... }\end{array}$ & $\begin{array}{l}\text { institutional rank, historical } \\
\text { and symbolic values }\end{array}$ & $\begin{array}{l}\text { readers' comfort and } \\
\text { enjoyment, and urban } \\
\text { insertion }\end{array}$ \\
\hline & portraits convey... & authority; respect & $\begin{array}{l}\text { informality; artistic } \\
\text { contribution }\end{array}$ \\
\hline
\end{tabular}




\begin{tabular}{|c|c|c|c|}
\hline \multicolumn{4}{|l|}{ Space appropriated } \\
\hline $\begin{array}{l}\text { appropriation (in } \\
\text { general) }\end{array}$ & & not afforded & afforded \\
\hline $\begin{array}{l}\text { collective reading } \\
\text { atmosphere }\end{array}$ & & $\begin{array}{l}\text { multifaceted, including } \\
\text { affective dimension }\end{array}$ & \begin{tabular}{|l|} 
plain, mainly \\
instrumental
\end{tabular} \\
\hline affective qualities & & $\begin{array}{l}\text { frequent lack of affective } \\
\text { relation to space; } \\
\text { tranquility }\end{array}$ & $\begin{array}{l}\text { positive relation to } \\
\text { space; tranquility, } \\
\text { organization, } \\
\text { concentration, } \\
\text { togetherness }\end{array}$ \\
\hline $\begin{array}{l}\text { outstanding } \\
\text { qualities }\end{array}$ & & heritage building & luminous; transparent \\
\hline social interaction & & not common & frequent \\
\hline $\begin{array}{l}\text { adults reading } \\
\text { accompanied }\end{array}$ & & no & yes \\
\hline $\begin{array}{l}\text { public space } \\
\text { conceptualization } \\
\text { associated with... } \\
\end{array}$ & & public heritage building & $\begin{array}{l}\text { public service; social } \\
\text { diversity }\end{array}$ \\
\hline public sphere & & no activity observed & some activity \\
\hline $\begin{array}{l}\text { activities } \\
\text { propitiated }\end{array}$ & & no strolling reading & strolling reading \\
\hline \multirow{2}{*}{ gender issues: } & elder women absence & yes & yes \\
\hline & in-house reading & slight male predominance & balance men/women \\
\hline age issues & & $\begin{array}{l}\text { young-adult students feel } \\
\text { unwellcome }\end{array}$ & no \\
\hline \multirow{3}{*}{ class issues: } & manual workers & diminute presence & diminute presence \\
\hline & upper-class presence & not found & not found \\
\hline & $\begin{array}{l}\text { "marginals" } \\
\text { acceptance }\end{array}$ & no & nuanced \\
\hline
\end{tabular}

referred to as residents to serve as a pressure group. On the other hand, the researchers overheard comments by security personnel in AG who judged the residents as "not doing a thing in life, besides going there". We were surprised to notice that negative judgments about reading as leisure even surfaced with a library.

It should be noted that similar profiles have been identified in another city's library (Rodrigues 2007). Rodrigues' approach, however, did not take space use as a profile dimension. The inclusion of space allowed for a richer characterization of readers. It also unveiled additional forms of use in terms of space appropriation, namely that of butterflies, not previously documented, which would have remained invisible, were this dimension not included. 


\section{Conclusions and Recommendations}

This chapter has analyzed how readers, through their activities and relationships in two different spaces with different architectural and social properties, interact with each space to shape their reading practices. The chapter has also looked at how the use of space plays a role in defining user profiles.

Methodologically, the inclusion of spatial social relations in the research design was revealed to be fundamental for a comprehensive understanding of these interactions. It allowed the unveiling of a previously undocumented reading profile, that of strollers or butterflies. The research also revealed, through associating reading profiles and social inequalities with areas used in AG, how different regions may be created through the appropriation of different spaces through interaction. It should be noted that these regions do not necessarily coincide with the organization of library areas according to documents physical support. This methodology allowed the researchers to simultaneously look at readers as library and architecture users and to work together from two different discipline perspectives.

Different programs gave way to different architectural achievements and also to different usage experiences. Departing from the space provided, space was later appropriated, and social space was produced through the social relations performed while reading. Historically, library building typologies have responded more to institutional and LIS functional requirements (institution or object-centered projects, as in SL) than to readers requirements (user-centered projects, as in AG). The different user categories which were described reveal a multiplicity of unsuspected needs and relationships between users; between users and staff; and, between users and facilities. An example is the creation of reading places around AG's mezzanine which was not anticipated by the architect, the librarians or either of the researchers as a desirable space which would be appropriated for library use by readers.

Concepts such as openness and "publicness" may be translated into bricks and mortar, and then into "transparent" and "open" reading atmospheres, just as the absence of togetherness and the impossibility of meaningful appropriations into "isolated" and "de-personalized" atmospheres, or "control" and "heritage reverence" to "constrained" ones. The impact of such translations stresses the need to keep the government and its representatives accountable for clear democratic cultural policies for public libraries and for the transposition of such policies into the architectural briefs. The absence of clear concepts leaves all options in the hands of the architectural teams, who are not supposed to be familiar with readers' needs.

Buildings should provide enough differentiation and flexibility for personal or group appropriation of both space and resources, for readers with different expectations, ages, socio-cultural backgrounds and different skills. 
Space should provide both privacy and togetherness, a sense of order, here understood as a cultural and spatial reference, within a context where house and work spaces are usually encumbered with objects and noise. Space should also allow group work, social exchange and collective knowledge creation. Scale, spatiality, lighting, materials and colors should all contribute to build a warm atmosphere and a cultured one ("buildings of importance"), through both balance and harmony. The possibility of "coming in and out" at one's convenience is a clear advantage and existing surveillance should not curtail this. Furthermore, the research suggests that the more freely built, convivialityoriented and tranquil a reading atmosphere is, the larger will be the impact and variety of user actions in shaping a space. A massive use of ICT, both for organizational and management purposes (e.g. catalogs) as well as for readers use presents a challenge that architects must be aware of in order to develop adequate responses so that even when new forms of use, not yet acknowledged or identified, are being propitiated technologically.

Another major challenge is finding formal contemporary expressions which consistently avoid "urbanalizatión". Fostering the learning of how to use and understand these new spaces by users who may experience some difficulties and so feel disempowered that they are unable to find the means to develop themselves within these spaces also needs to be considered.

With regard to functional requirements, statements from the readers show that there are unexpected needs which go beyond the traditional concepts of a library. These needs are distant from the reductive "historical archive in the Internet age". These practices may only be understood in the context of the city, housing and present-day conditions of life. The library is (increasingly) a civic centre, and so no cultural or leisure activities should be ignored, a priori. Readers value free public resources such as libraries and most deprived users are, as might be anticipated, the most sensitive to the economic advantages that such spaces provide.

The two cases that have been studied demonstrate how different visions of what a public library is built for reflect on the space provided as well as allowing for or hindering users' appropriations. These spaces, along with different management policies, shape readers' practices and behaviors, contributing to the production of reading atmospheres with dissimilar and even opposing features.

The wealth of collections, the ease of access to facilities - from transportation, opening hours, the absence of architectural barriers, staff support, spatial conception - from light design to choice of materials for building and furnishings - representations of the use of a "building of importance" as a privilege and the provision of attractive reading environments, all of these contribute to a reinforcement of the Commons. Developing the interaction between libraries and their immediate surroundings, which appeared under-explored in both cases, would widen the range of possibilities of library usage by the ability to 
enjoy nature might also contribute to these Commons. Very different modes of use are enacted by readers, along with different modes of occupation - permanence, migration or occasional visits. The interaction among different areas for reading and other purpose spaces should also promote a comprehensive use of both buildings and areas of urban insertion. All of this calls for the provision of open, diversified, non-directive, democratic spaces to accommodate all users and their needs. Allowing for readers' appropriation and transformation, a reasonable balancing of the issues of rights and legitimacy with preservation and control, propitiating plural affective atmospheres are among the things that could enhance spatial experience and social life. Furthermore, publicly available services, expertise as well as material and informational resources should be used in rational and sustainable ways. These could set exemplary cases of providing public spaces for readers as opposed to current trends of individualization which invade and disrupt our daily lives. From a social justice standpoint, the participation of readers in design and use issues should be encouraged, from public debates to having representation on managerial advisory bodies. Their views, as final users, should be taken into account in the design of architectural briefs as well as from the practical perspective of efficiency and adequacy in space use.

Reading a space may not be a conscious, reflected process, but the way one enacts spatial social relations provides clues on tacit use rules, on existing social atmospheres. Clues are picked up from body postures and behaviors as well as from simple and adaptable or imposing and rigid designs. It may be difficult for users to comment on architectural features, but their responses to such spaces are eventually reflected in their description and evaluation of the reading atmospheres. These atmospheres may be read as welcoming or, on the contrary, as keeping some at large by symbolically signaling whether they fit in or not. Embodied rules of space which foster social diversity should be a matter of concern in the same way as formal rules of use. One of the TV sets in AG might play films from a programmed schedule, occasionally incorporating users' suggestions. If all the equipment is put to use, more films could be viewed and conflicts over individual appropriations could be reduced.

Conviviality emerged as one of the most cherished dimensions of a reading atmosphere, according to reader's statements. Social class, age, ethnicity or gender diversity should be encouraged as an ethical principle for the benefit of these groups themselves but also for others. Such an environment would also allow the mingling and mixing of all kinds of people, as the adjective public implies and effective democratic policies demand. Needs for privacy or personal place making should not be mistaken for segregation, totally isolating areas or entrances - such as young readers' or reading seats. Affective bonding may be hindered and, after all, conviviality is one of the main reasons people go to libraries, even for those who can afford similar resources at home. 
Further research should be undertaken to understand how architectural design may be developed - along with managerial specific requirements - to accomplish the partially unfulfilled aim of providing a place for those who have no books and no reading habits.

\section{Acknowledgements}

We wish to thank Eva Lima (EL) and Ricardo Sequeiros Coelho (RSC) for allowing the use of their pictures. Other illustrations were made by the authors.

\section{References}

Aabø, S., Audunson, R. and Vårheim, A. "How do public libraries function as meeting places?" Library \& Information Science Research, 32.1 (2010): 16-26.

American Library Association. "New survey shows U.S. public libraries in financial jeopardy: cuts reduce hours, staffing at thousands of libraries as patron demand escalates." 14 Jan. 2010.

www.ala.org/ala/newspresscenter/news/pressreleases2010/january2010/trendstudy_ors. cfm [Mar. 2011].

Alstad, C. and Curry, A. "Public space, public discourse, and public libraries." LIBRES, 13.1 2003. http://libres.curtin.edu.au/libres13n1/index.htm [Mar. 2011].

Audunson, R. "The public library as a meeting-place in a multicultural and digital context: The necessity of low-intensive meeting-places." Journal of Documentation, 61.3 (2005): 429-441.

Audunson, R., et al. "Public libraries, social capital and low intensive meeting places." Information Research, 12.4 (2007): 1-13.

Bakardjieva, M. "Virtual togetherness: an everyday life perspective." Feenberg, A. and Barney, D., eds. Community in the Digital Age: Philosophy and Practice. Lanham: Rowman and Littlefield, 2004.

Bertot, J. C., et al. "Public libraries and the Internet 2008-2009: issues, implications, and challenges." First Monday, 14.11 (2 Nov. 2009).

http://firstmonday.org/htbin/cgiwrap/bin/ojs/index.php/fm/rt/printerFriendly/2700/2351 [Mar. 2011].

Bertrand, A. M. "Cris et chuchotements." Bulletin des Bibliothèques de France, 39. (1994): 8-13.

Biblioteca Pública Municipal do Porto. Biblioteca Pública Municipal do Porto: Documentos para a sua História. Porto: Imprensa Portuguesa, 1933.

-. Biblioteca Pública Municipal do Porto: Exposição no $150^{\circ}$ Aniversário da sua Fundação. Porto: BPMP, 1984.

Blumer, H. Symbolic Interactionism. Englewood Cliffs: Prentice-Hall, 1969.

Bourdieu, P. Distinction: A Social Critique of the Judgment of Taste, trans. Richard Nice Cambridge, MA: Harvard University Press, 1984, 474

-. "The genesis of the concepts of habitus and field." Theories and Perspectives, 2.2 (1985): $11-24$. 
Bourdieu, P. and Darbel, A. L'Amour de L'Art: Les Musées et Leur Public. Paris: Les Éditions de Minuit, 1966.

Bruno, S. "A bibliotheca publica do Porto: I sua fundação e instalação.” Serões: $2^{\mathrm{a}}$ série, 3.16 (1906): 200-300.

Bull, M. "Investigating the culture of mobile listening: from Walkman to iPod." Bull, M., O'Hara, K. and Brown, B., eds. Consuming Music Together: Social and Collaborative Aspects of Music Consumption Technologies. Dordrecht: Springer, 2006.

Burawoy, M. "The extended case method." Sociological Theory, 16.1 (1998): 4-33.

Buschman, J. "On Libraries and the Public Sphere." Library Philosophy and Practice, 7.2 (2008): 1-9.

Cérézuelle, D. Crise du Savoir Habiter, Exclusion Sociale et Accompagnenent à L'autoréhabilitation du Lodgement. Paris: IDDRI, 2007.

www.iddri.org/Publications/Collections/Idees-pour-le-debat/id_0705_cerezuelle_ svrfairelocx.pdf [Aug. 2010].

Certeau, M. de. The Practice of Everyday Life. Berkeley: U of California P, 1984.

Donmoyer, R. "Generalizability and the single case study." Gomm, R., Hammersley M. and Foster, P., eds. Case Study Method: Key Issues, Key Texts. London: Sage, 2000.

Eder, D. and Fingerson, L. "Interviewing children and adolescents." Gubrium, J. F. and James, A., eds. Handbook of Interview Research: Context and Method. Thousand Oaks: Sage, 2002.

Eigenbrodt, O. "Designing Library Facilities for Everyone? Providing Space for Informational Participation." Hauke, E. A. Petra, ed. Providing Access to Information for Everyone. 16th BOBCATSSS Symposium 2008, Zadar, Croatia. Berlin: Humboldt Universität, 2008.

-. "Societal Places: The constitution of library space through activity." World Library and Information Congress, 74th IFLA General Conference and Council, Québec. Proceedings. The Hague: IFLA, 2008a.

Fernandes, L. "A imagem predatória da cidade.” Cordeiro, G. Í., Baptista, L. V. and Costa, A. F. da, eds. Etnografias Urbanas. Oeiras: Celta, 2003.

Finlayson, A. "No shushing in this library." San Diego Reader, 18 June 2008.

Fisher, K. E., et al. "Seattle Public Library as place: reconceptualizing space, community, and information at the Central Library." Buschman, J. E. and Leckie, G. J., eds. The Library as Place. Westport, CT: Libraries Unlimited, 2007.

Fortuna, C., et al. Sobre a Leitura. Lisboa: IPLB, Observatório das Actividades Culturais, 1999.

Fraser, N. "Rethinking the Public Sphere: a contribution to the critique of actually existing democracy." Calhoun, C., ed. Habermas and the Public Sphere. Cambridge, MA: MIT Press, 1992.

Freitas, E. D., Casanova, J. L. and Alves, N. D. A. Hábitos de Leitura: Um Inquérito à População Portuguesa. Lisboa: Dom Quixote, 1997.

Geertz, C. C. The Interpretation of Cultures. London: Hutchinson, 1975.

Given, L.M. and Leckie, G.J. "'Sweeping' the library: mapping the social activity space of the public library 1." Library and Information Science Research, 25 (2003): 365-385.

Habermas, Jurgen. The Structural Transformation of the Public Sphere. Cambridge (MA): MIT Press. 1989.

Haraway, D. "A manifesto for cyborgs: science, technology and socialist feminism in the 1980s." Haraway, D., et al. Simians, Cyborgs and Women: The Reinvention of Nature. New York: Routledge, 1991. 
-. "Situated knowledges: the science question in feminism and the privilege of partial perspective." Feminist Studies, 14.3 (1988): 575-599.

Illich, I. "Une société sans école." Oeuvres Complètes 1. Paris: Fayard, 2005.

Klein, N. "Why Being a Librarian is a Radical Choice." Dissident Voice, 15 July 2003. www.dissidentvoice.org/Articles7/Klein_Librarian.htm [Mar. 2011].

Kvale, S. Interviews: An Introduction to Qualitative Research Interviewing. Thousand Oaks: Sage, 1996.

Laidler, J. "Library use rises as economy falls.” The Boston Globe, 16 Oct. 2008. www.boston.com/news/local/articles/2008/10/16/library_use_rises_as_economy_falls [Mar. 2011].

Leckie, G. J. "Three perspectives on libraries as public space.” Feliciter, 6 (2004): 223-236.

Leckie, G. and Hopkins, J. "The public place of central libraries: findings from Toronto and Vancouver." Library Quarterly, 72.5 (2002): 326-372.

Lefèbvre, H. The Production of Space. Oxford: Blackwell, 1991.

Lizdas, W. J. "Libraries' many benefits rediscovered in hard economic times." JSOnline, 21 Jan. 1991. www.jsonline.com/news/38082709.html [Mar. 2011].

Mattern, S. "Resonant texts: Sounds of the American public library." Society, 2.3 (2007): 277-302.

Miribel, M. D. "Chut! Vous faites trop de bruit!: quel silence en bibliothèque aujourd'hui?" Bulletin des Bibliothèques de France, 52.4 (2007): 76-83.

Muñoz, F. UrBANALización: Paisajes Comunes, Lugares Globales. Barcelona: Gili, 2008.

Oblander, T. "Economy gets people out of the house, into libraries." The Houston Chronicle. 2 Aug. 2008. www.chron.com/disp/story.mpl/nation/5920609.html [Mar. 2011].

Passos, S. M. Depois de Pinakes. Master's Thesis. Porto: Universidade do Porto, 2010.

Pereira, V. B. Classes e Cultura de Classes. Porto: Afrontamento, 2005.

-. "Distinction comes to Porto." Practicing Pierre Bourdieu Conference, Panel VI. At Ground Level: Physical Space and Lived Social Space. Ann Arbour: U of Michigan. 2006. http://repositorio-aberto.up.pt/handle/10216/14184 [Mar. 2011].

Petit, M. Lecturas. Mexico: Fondo de Cultura Económica, 2001.

Pirodi, E. "Uso sociale dello spazio publico nella città contemporanea." Mattogno, C. Idee di spazio, lo spazio nelle idée. Milano: Franco Angeli, 2002.

Rodrigues, E. A. "A biblioteca e os seus públicos: uma proposta interpretativa." Sociologia, Problemas e Práticas, 53 (2007): 135-157.

Santos, C. dos. "O Porto e a instrução pública: a Academia Real da Marinha e Comércio (1803-1837)." Estudos em Homenagem ao Professor Doutor José Marques, 1. 2006. http://repositorio-aberto.up.pt/handle/10216/8971 [Mar. 2011].

Seale, C., ed. Researching Society and Culture. 2nd ed. London: Sage, 2004.

Sequeiros, P. "User profiles: from a qualitative case study approach to providing a better service." Katsirikou, A. and Skiadas, C. H., eds. Qualitative and Quantitative Methods in Libraries: Theory and Applications. Proceedings of the International Conference on QQML 2009. Singapore: World Scientific Publishing, 2010.

-. "The social weaving of a reading atmosphere." Journal of Librarianship and Information Science, (2011). In press.

Taipale, K. "From Piazza Navona to Google or, from local public space to global public sphere." Paper presented at Public Spheres and Their Boundaries Conference. University of Tampere. 2006.

www.uta.fi/laitokset/tacs/papers0506/Paper_PUBLIC_SPACE_UTA_conference_May 06_taipale.pdf [Mar. 2011]. 
288 Paula Sequeiros and Silvia Grünig

Tonkiss, F. Space, the City and Social Theory: Social Relations and Urban Forms. Cambridge, MA.: Polity, 2005.

Wirth, L. "Urbanism as a way of life." Reiss, J. A. J., ed. On Cities and Social Life. Chicago: U Chicago P, 1964. 